\title{
Early on Set Presbyacusis in Gwagwalada Area Council of Federal Capital Territory, Abuja
}

\author{
David Femi Folorunso ${ }^{1}$, Enoch Auta Dahilo1, Ibeneche Onyemuchechi Gbujie1, \\ Fredrick M. Damtong1, Oladeji Raheem Quadri², Basil E. Nwankwo ${ }^{3}$, \\ Titus Sunday Ibekwe1, Onyekwere George Nwaorgu4
}

\author{
${ }^{1}$ Department of ENT/Head \& Neck Surgery, University of Abuja Teaching Hospital, Gwagwalada-Abuja, Nigeria. \\ ${ }^{2}$ Department of ENT, Federal Teaching Hospital Gombe, Gombe State, Nigeria \\ ${ }^{3}$ Chukwuemeka Odumegwu Ojukwu University Teaching Hospital, Awka Anambra State, Nigeria \\ ${ }^{4}$ Department of Otorhinolaryngology, University College Hospital, Ibadan \& College of Medicine, University of Ibadan, Oyo State, \\ Nigeria \\ Email: *dave_bose@yahoo.com, davebose74@gmail.com
}

\begin{abstract}
How to cite this paper: Folorunso, D.F., Dahilo, E.A., Gbujie, I.O., Damtong, F.M., Quadri, O.R., Nwankwo, B.E., Ibekwe, T.S. and Nwaorgu, O.G. (2021) Early on Set Presbyacusis in Gwagwalada Area Council of Federal Capital Territory, Abuja. International Journal of Otolaryngology and Head \& Neck Surgery, 10, 238-249.
\end{abstract} https://doi.org/10.4236/ijohns.2021.103022

Received: March 8, 2021

Accepted: May 24, 2021

Published: May 27, 2021

Copyright () 2021 by author(s) and Scientific Research Publishing Inc. This work is licensed under the Creative Commons Attribution International License (CC BY 4.0).

http://creativecommons.org/licenses/by/4.0/ (c) (i) Open Access

\begin{abstract}
Background: Presbyacusis is a major cause of hearing loss among seniors. The condition attracts attention following the prediction of World Health Organization that elderly population is expected to hit 1.2 billion by 2025 out of which more than 500 million of them will suffer from sensorineural hearing loss(SHL) worldwide. The studies have shown that this begins to reflect on audiograms as from the third decade, mainly in the high frequencies. Aim/objective: This study evaluated the early on-set presbyacusis at Gwagwalada Area Council of the Federal capital territory-Abuja. Method: It was a multi-stage sampling, prospective, cross-sectional study done in FCT, Abuja. Participants from age 20 years and above were recruited into the study after signing informed consent. The presumed risk factors as highlighted in the questionnaire were screened out. Results: Two hundred and two participants were recruited into the study, out of which twelve were excluded from the analysis on account of various exclusion criteria. The age range of the participants was 20 to 79 years, with an average age of $54.8 \pm 5.6$ years. One hundred and fourteen $(60.0 \%)$ males and seventy-six (40.0\%) females participated in the study. The commonly reported associated symptom was tinnitus. About $32.0 \%$ of the participants had moderate sensorineural hearing loss. However, the prevalence of presbyacusis was $28.2 \%$ for age below 65 years and $78.8 \%$ for 65 years and above. The cumulative prevalence was $54.2 \%$. Conclusion: The study has shown that presbyacusis occur as early as the third decade of life, possibly subclinical before age 65 years. The prevalence was $28.2 \%$ before
\end{abstract}


age 65 years and $78.8 \%$ from age 65 years, there was a steady increase in percentage of participants with SNHL from age 20 years, and a significant sudden increase from 65 years was observed with a sloping tracing at high frequency.

\section{Keywords}

Presbyacusis, Age-Related Hearing Loss, Young Adults, Sensorineural Hearing Loss, and Pure Tone Audiometry

\section{Introduction}

Presbyacusis is a slow, progressive loss in hearing due to aging process, also called age-related hearing loss. Is one of the main causes of hearing loss among the aged and consider to commence from 65 years [1]? This has attracted attention of otorhinolaryngologists and audiologists across the globe. The attention has increasingly become pronounced following the prediction of World Health Organization, that elderly population is expected to hit 1.2 billion by 2025 out of which more than 500 million of them will suffer from sensorineural hearing loss (SNHL) worldwide [2]. Apart from high decibel loss at high frequencies there were documentations on affectation of low, and middle frequencies depending on the duration. Presbyacusis has been shown in many studies to have incredibly negative effects on the quality of life of millions of seniors [3]. The loss oftentimes is symmetrical, which is sensorineural hearing loss over a long period of time. Presbyacusis is a common global hearing problem [4] [5]. Hearing acuity deteriorates with age. Studies have shown that this begins to reflect on audiograms as from the third decade, mainly in the high frequencies and also associated with hearing loss at speech frequencies which begin to manifest as from the fifth decade of life [6].

The study was set out to verify some of the studies that have shown high frequency loss beginning from the third decade, age twenty and above is WHO cut off for adulthood.

Age-related hearing loss (ARHL) is related to functional loss of sensory and neural elements [1] [7] [8]. Presbyacusis generally affects all parts of the ear, but the ultimate clinical impact is on cochlear [8]. Hearing aid (HA) remains popular treatment of choice. Some patients with presbyacusis do not benefit from HA due to degree of hearing loss, especially, those with severe to profound SNHL which may benefit from cochlear implants. Multi-disciplinary approach involving the fields of otolaryngology, audiology, neurology, and psychology is needed for effective management of age related hearing loss [9].

\section{Aim and Objective}

This study evaluated the early on-set presbyacusis at Gwagwalada Area Council of the Federal capital territory-Abuja. 


\section{Subjects and Methods}

The study was carried out in different communities, within ten wards of Gwagwaglada Area Council of FCT Abuja, Nigeria (Community based study), between January 2014 and May 2017 in which consenting and eligible participants aged 20 years and above were recruited. A multi-staged sampling technique was adopted for the study and sample size was determined using Leslie and Kish method $\left(\mathrm{N}=\mathrm{Za}^{2} \mathrm{P}(1-\mathrm{P}) / \mathrm{d}^{2}\right)$. Gwagwalada area council has 10 electoral wards. Twenty participants were selected in each of the eight wards, and twenty one each in the remaining two wards by using kish selection method in selecting participants.

Questionnaires were used to obtain the subject's demographic and clinical data from participants after which participants ears were examined to rule out other possible causes of hearing loss, age, and gender then became a major variable. Otoscopy was done using Welch Allyn Diagnostic Otoscope [10] to ensure that the ear was free of cerumen, ear discharge or tympanic membrane perforation. The sound level meter was used to determine the tolerable ambient noise level in the facility environment provided by the household of participant. The meter was held at arm's length. Other specific instructions from the manual were observed. Measurements were performed at each measurement site by recording the noise level at an interval of 5 minutes. Average noise level was taken from five readings made at each noise source [11]. Permissible ambient noise level for pure tone audiometry (PTA) was maintained between 25 to $35 \mathrm{dBHL}$. Subsequently, tympanometry and PTA were done on all the patients. Tympanometer was used first, by using dully calibrated Micro Tympanometer by Welch Allyn Inc, to rule out middle ear pathology, following standard steps and Type A (Normal middle ear function) [12] [13] participants were selected. Audiometry was done immediately for all these participants without middle ear pathology. Following Standard steps [12] [13]. Statistical product and service solutions (SPPS) version 20 was used to evaluate and analysed my data.

\section{Results}

Two hundred and fourteen participants were recruited into the study, after various presumed risk factors as highlighted in the questionnaire were screened out, which included hearing loss, noise induced hearing loss, diabetes, hypertension, ototoxic drugs, otologic disorders, e.g. Meniere's disease, autoimmune hearing loss, syndromic hearing loss, suppurative otologic disease, ear surgeries etc. After otoscopy, two hundred and twelve continued with the study (Table 1). During tympanometry assessment, twenty two were excluded from the analysis on account of exclusion criteria (Table 2). The remaining participants (one hundred and ninety) all went through the next stage of the study. The age range of the participants was 20 to 79 years, with a mean age of $54.8 \pm 5.6$ years. One hundred and fourteen (60\%) males and seventy six (40\%) females participated in the study (Table $3 \&$ Table 4). Majority of the participants (39.0\%) were of the 
Hausa ethnicity (dominant tribe in the study area).

Analysis of variance of participants with hearing impairment and those with normal hearing threshold revealed that gender $(P=0.717)$ and Tribe $(P=0.361)$ were not significant in the development of early on set presbyacusis (Table 4).

The pattern of hearing threshold among the participants were shown in (Table 5 \& Table 6). Audiometry evaluation further showed that one hundred and three of them $(54.2 \%)$ had normal hearing threshold in both ears and eighty seven $(45.8 \%)$ participants had one form of hearing loss in one or both ears. Majority of them had moderate sensorineural hearing loss and 2 participants had profound hearing loss (Table 5). The prevalence of hearing loss generally was high in the study (Table 6). However, the study showed that participants below age sixty five had more normal hearing threshold (Table 7), and those with hearing impairment were also seen more having mild sensorineural hearing loss. None of them below this age had profound hearing loss (Table 7), and the participants with moderate and severe sensorineural hearing loss was also low compare to above 65 years. The frequencies of the hearing loss were mainly in the high frequencies, except among participants above sixty five with some having mid frequencies and low frequencies. The prevalence of hearing loss increased in number with age (Table 8). The commonest associated symptoms was tinnitus, which was also prominent among participants above sixty five years, all but five participants above this age group complained of tinnitus (Table 9), compare to age below sixty five where only seven of them complained of tinnitus.

Table 1. Otoscopic finding during screening of participants.

\begin{tabular}{ccc}
\hline Otoscopic finding & Right & Left \\
\hline Wax impaction & 15 & 13 \\
TM perforation & 2 & 1 \\
Intact TM & 197 & 200 \\
Total & 214 & 214 \\
Participants with normal findings after ear syringing & 212 & 212 \\
\hline
\end{tabular}

Table 2. Tympanometric findings in 212 participants screened with otoscopy.

\begin{tabular}{ccc}
\hline Types & Right Ear & Left Ear \\
\hline$A$ & 190 & 190 \\
$A s$ & 5 & 4 \\
$A d$ & 14 & 14 \\
$B$ & 3 & 2 \\
$C$ & Nil & 2 \\
Total & 212 & 212 \\
\hline
\end{tabular}


Table 3. Demographic data of participants with age related hearing loss.

\begin{tabular}{cccc}
\hline Age group & $\begin{array}{c}\text { Total } \\
\mathrm{N}=190\end{array}$ & $\begin{array}{c}\text { Male } \\
\mathrm{n}=114\end{array}$ & $\begin{array}{c}\text { Female } \\
\mathrm{n}=76\end{array}$ \\
\hline $20-29$ & 29 & 16 & 13 \\
$30-39$ & 15 & 9 & 6 \\
$40-49$ & 30 & 16 & 14 \\
$50-59$ & 30 & 18 & 12 \\
$60-69$ & 62 & 39 & 23 \\
$70-79$ & 24 & 16 & 8 \\
\hline
\end{tabular}

Table 4. Demographic data of participants with age related hearing loss.

\begin{tabular}{ccc}
\hline & Test $\mathrm{n}=95$ & \\
\hline Gender & Frequency (\%) & P-value \\
\hline Male & $114(60.0)$ & $<0.001$ \\
Female & $76(40.0)$ & \\
Tribe & & \\
Yoruba & $22(11.6)$ & \\
Ibo & $18(9.5)$ & \\
Hausa & $51(26.8)$ & \\
Others & $99(52.1)$ &
\end{tabular}

Table 5. Audiometry outcome.

\begin{tabular}{ccccc}
\hline & Test right (\%) & Test left (\%) & Odd ratio (CI) & P-value \\
\hline Normal & $76(40.0)$ & $73(38.4)$ & $16.545(7.715-35.484)$ & $<0.001$ \\
MILD & $28(14.7)$ & $28(14.7)$ & $1.183(0.529-2.643)$ & 0.838 \\
Moderate & $62(32.6)$ & $76(40.0)$ & $0.113(0.054-0.238)$ & $<0.001$ \\
Severe & $22(11.6)$ & $11(5.8)$ & $0.188(0.061-0.579)$ & 0.002 \\
Profound & $2(1.1)$ & $2(1.1)$ & - & 0.497 \\
Total & $190(100.0)$ & $190(100.0)$ & & \\
\hline
\end{tabular}

Table 6. Prevalence of presbyacusis.

\begin{tabular}{cccc}
\hline & Test $\mathrm{n}$ & Prevalence $\%$ & p-value \\
\hline Normal hearing & 87 & 45.8 & $<0.001$ \\
SNHL & 103 & 54.2 & \\
Total & 190 & 100 & \\
\hline
\end{tabular}


Table 7. Comparism of prevalence of presbyacusis below and above 65 years.

\begin{tabular}{cccc}
\hline & $<65$ years & 65 years \& above & 20 to 79 years \\
\hline Normal hearing & 89 & 14 & 103 \\
SNHL (mild-Profound) & 35 & 52 & 67 \\
Total & 124 & 66 & 190 \\
Prevalence (\%) & 28.2 & 78.8 & 54.8 \\
\hline
\end{tabular}

Table 8. Prevalence of hearing loss in an increase order of age bracket.

\begin{tabular}{ccccc}
\hline Age group & Total No. & $\begin{array}{c}\text { Normal hearing } \\
\text { (Bilateral) }\end{array}$ & SNHL (no) & $\begin{array}{c}\text { Age group } \\
\text { Prevalence (\%) }\end{array}$ \\
\hline $20-29$ & 29 & 27 & 2 & 6.9 \\
$30-39$ & 15 & 13 & 2 & 13.3 \\
$40-49$ & 30 & 24 & 6 & 20.0 \\
$50-59$ & 30 & 20 & 10 & 33.3 \\
$60-69$ & 62 & 17 & 45 & 72.6 \\
$70-79$ & 24 & 2 & 22 & 91.0 \\
Total & 190 & 103 & 87 & \\
\hline
\end{tabular}

Table 9. Associated symptom (tinnitus).

\begin{tabular}{cccccc}
\hline & \multicolumn{2}{c}{ Test (below 65 years $)$} & \multicolumn{2}{c}{ Test $(65$ years and above $)$} & \multirow{2}{*}{ p-value } \\
\cline { 2 - 4 } & Frequency & Percentage & Frequency & Percentage & \\
\hline Yes & 7 & 3.2 & 61 & 98.9 & $<0.05$ \\
No & 117 & 96.8 & 5 & 1.1 & \\
Total & 124 & 100.0 & 66 & 100.0 & \\
\hline
\end{tabular}

\section{Discussion}

The study assessed the prevalence of presbyacusis from 20 years and above at Gwagwalada area council to be $54.2 \%$. However, the prevalence below age sixty five years was found to be $28.2 \%$ and from age 65 years was $78.8 \%$. The study has also confirmed progressive rise in sensorineural hearing loss with age, irrespective of other socioeconomic and lifestyle. As much as possible co-founding factors (noise induced hearing loss, diabetes, hypertension, ototoxic drugs, otologic disorders, autoimmune hearing loss, syndromic hearing loss, ear surgeries) were eliminated via the exclusion criteria. Age remains most significant factor for developing presbyacusis which is in consonance with studies done by Moscicki et al. [14], Wallhagen [15] and Strawbridge [16].

The finding in this study is also in agreement with the one conducted by Bazaran et al. [17] among aged African Americans. Gates and Mills also noted that, symmetrical, sensorineural hearing loss is expected as we advance in age irres- 
pective of other risk factors [3]. This supports the fact that incomprehensible hearing loss in an aged can be attributed to aging and by extension in this study, any SNHL with features of Presbyacusis below age 65 years should be considered as an early onset variety having excluded other causes. This makes presbyacusis a diagnosis of exclusion.

The studies done in the South West Nigeria showed low prevalence. Afolabi et al. in Ibadan also reported a lower prevalence of $24.7 \%$ from age 65 years [4]. The prevalence of $78.8 \%$ among elderly is high when compared with those previous studies done in Nigeria.

The prevalence among the elderly is high in Gwagwalada area council compared to prevalence in UK, which was between 30\% and 65\% [5] [18] high in comparison to the $43 \%$ prevalence reported in US among the senior citizens from 65 years-84 years [19] [20] [21]. Is also high compare to Lasisi et al. in Ibadan which showed $6.1 \%$ as prevalence in 1302 elderly people living in Ibadan Nigeria [22].

There was sudden surge of prevalence of presbyacusis from age 60 years, when compare to prevalence between age 40 to 59 years. This suggests that presbyacusis becomes most significant as from sixth decade which is inconsonance with the WHO age demarcation for the elderly. From 70 years the prevalence was $91 \%$, which was significantly high compare to study done in USA. However, the various studies done showed steady increase in prevalence as from age 65 years [19] [20] [21] which was the same in this study. No cultural practices was identified as possible factor to explain this high level of hearing loss in Gwagwalada area council. The univariant analysis regarding, tribes, and other demographic factors were insignificant. This calls for more studies in the northern part of Nigeria, if there could be any regional factors in the northern part of Nigeria responsible for this. Genetics remains another important aspect to be unraveled for possible explanation of this high prevalence. Studies on genetics, climate impacts, and others on age related hearing loss is recommended.

Majority (38.8\%) in this study had moderate SNHL. This is similar to the report of Sogebi in the assessment of predisposing factors for hearing loss in adult Nigerian population [23].

Participants with tinnitus above 65 years was found to be significantly high in this study (98.9\%), this compares with previous study by Sogebi in Sagamu, Southwest Nigeria, where tinnitus was reported to be as high as $79.7 \%$ among the participants with SNHL [23]. However, the study by Lasisi et al. [22] in Ibadan among the elderly with SNHL had a $14.1 \%$ prevalence. An important trend noticed in the studies done so far in Nigeria and my study revealed the same, that tinnitus is the major associated symptoms with presbyacusis, thus, show a strong association between them.

This study has shown that SNHL, high frequency loss, starts with some persons from third decade of life and became prominent from age fifty, as against the popular consensus that presbyacusis is found among the elderly, from age 65 
years according to the WHO definition of elderly. Subclinical (mild) SNHL loss below age 50 years, and small percentage of people with this problem could also be the reason for less self-reported cases of presbyacusis. This study calls for a review of age definition of presbyacusis and more studies to find other co-finding factors, environmental impact, genetics and racial factors. Finally, if presbyopia which is also an aging process starts at 40 years why do we think prebyacusis starts at 65 years [24].

Irrespective of the age presbyacusis starts, measures or rehabilitative practices are not seen in our society because of lack of awareness, and no supporting group to take up this task for them. In most countries where these rehabilitation are effective, there is political will on the side of government to provide subsidy, platform and policy for all of these. Good digital hearing aid in our country is very expensive which majority of them cannot avoid, and hallmark for rehabilitation is hearing aid, combine with all of above measures.

One major limitation in this study is age estimation for few participants who were not sure of their accurate date of birth. Inability to use MRI is also part of our limitations in this study. However, structural deformities and swannomas are very rare $(0.8$ per 100,000$)$ as cause of hearing loss worldwide. Extremenly rare in our environment. The audiometry features also helped to make the diagnosis of presbyacusis which was an important guide to our study.

\section{Conclusion}

The study has shown that Presbyacusis occur as early as the third decade of life in our environment. The prevalence of age related hearing loss in Gwagwalada Area Council of Federal Capital Territory was 28.2 before age 65 years and 78.8 from age 65.

\section{Conflicts of Interest}

The authors declare no conflicts of interest regarding the publication of this paper.

\section{References}

[1] Nelson, E.G. and Hinojosa, R. (2006) Presbycusis: A Human Temporal Bone Study of Individual with Downward Sloping Audiometric Patterns of Hearing Loss and Review of the Literature. Laryngoscope, 116, 1-12. https://doi.org/10.1097/01.mlg.0000236089.44566.62

[2] Begg, S., Vos, T., Baker, B., Stevenson, C., Stanley, L. and Lopez, A. (2007) The Burden of Disease and Injury in Australia 2003. PHE 82, Australian Institute of Health and Welfare, Canberra.

[3] Gates, G.A. and Mills, J.H. (2005) Presbycusis. The Lancet, 366, 1111-1120. https://doi.org/10.1016/S0140-6736(05)67423-5

[4] Afolabi, O.A. and Ijaduola, G.T.A. (2008) Pattern of Ear Diseases among Older People. East and Central African Journal of Surgery, 13, 96-100

[5] Ologe, F.E., Segun-Busari, S., Afolabi, O.A. and Abdulraheem, I.S. (2005) Ear Dis- 
eases in Elderly Hospital Patients in Nigeria. The Journals of Gerontology: Series A, 60, 404-406. https://doi.org/10.1093/gerona/60.3.404

[6] International Organization for Standardization (2000) Acoustics-Stastical Distribution of Hearing Thresholds as a Function of Age. ISO 7029: 2000, International Organization for Standardization, Geneva.

[7] Soucek, S., Michaels, L. and Frohlich, A. (1986) Evidence for Hair Cell Degeneration as the Primary Lesion in Hearing Loss of the Elderly. Journal of Otolaryngology, 15, 175-183.

[8] Frisina, R. and Walton, J. (2006) Age-Related Structural and Functional Changes in the Cochlear Nucleus. Hearing Research, 216-217, 216-223.

https://doi.org/10.1016/j.heares.2006.02.003

[9] Lindemann, A. (2015) Alpha Lipoic Acid May Slow down Aging. Juvenon Health Journal. http://www.juvenon.com/new-study-proves-alpha-lipoic-acid-may-slow-down-aging

[10] Welch Allyn (n.d.) MicroTymp 3 Portable Tympanometric Instrument. www.welchallyn.com

[11] Omokhodion, F.O., Adeosun, A.A. and Fajola, A.A. (2007) Hearing Impairment among Mill Workers in Small Scale Enterprises in Southwest Nigeria. Noise Health, 9, 75-77. https://doi.org/10.4103/1463-1741.36983

[12] Smith, R.J.H., Eliot Shearer, A., Hildebrand, M.S. and Van Camp, G. (2014) Deafness and Hereditary Hearing Loss Overview. Genes Review, 512-518.

[13] SydneyTAFE Wikispaces Network. https://www.Audiometry.sydneyinstitute.wikispaces.net

[14] Moscicki, E.K., Elkins, E.F., Baurn, H.M. and McNamara, P.M. (1985) Hearing Loss in the Elderly: An Epimediology Study of the Framingham Heart Study Cohort. Ear and Hearing, 6, 184-190. https://doi.org/10.1097/00003446-198507000-00003

[15] Walhagen, M.I., Strawbridge, W.J., Cohen, R. and Kaplan, G.A. (1997) An Increasing Prevalence of Hearing Impairment and Associated Risk Factors over Three Decades of the Alameda County Study. American Journal of Public Health, 87, 440-442. https://doi.org/10.2105/AJPH.87.3.440

[16] Strawbridge, W.J., Walhagen, M.I., Shema, S.J. and Kaplan, G.A. (2000) Negative Consequences of Hearing Impairment in Old Age: A Longitudinal Analysis. The Gerontologist, 40, 320-326. https://doi.org/10.1093/geront/40.3.320

[17] Bazargan, M., Baker, R.S. and Bazargan, S.H. (2001) Sensory Impairment and Subjective Well-Being among Aged African-American Persons. The Journals of Gerontology: Series B, 56, P268-P278. https://doi.org/10.1093/geronb/56.5.P268

[18] Frolenkov, G.I., Belyantseva, I.A., Friedman, T.B. and Griffith, A.J. (2004) Genetic Insights into the Morphogenesis of Inner Ear Hair Cells. Nature Reviews Genetics, 5, 489-498. https://doi.org/10.1038/nrg1377

[19] Gates, G.A. and Cooper, J.C. (1991) Incidence of Hearing Decline in the Elderly. Acta Oto-Laryngologica, 111, 240-280. https://doi.org/10.3109/00016489109137382

[20] Helzner, E.P., Cauley, J.A., Pratt, S.R., Wisniewski, S.R., Zmuda, J.M., Talbott, E.O., et al. (2005) Race and Sex Differences in Age-Related Hearing Loss: The Health, Aging and Body Composition Study. Journal of the American Geriatrics Society, 53, 2119-2127. https://doi.org/10.1111/j.1532-5415.2005.00525.x

[21] Gopinath, B., Rochtchina, E., Wang, J.J., Schneider, J., Leeder, S.R. and Mitchell, P. (2009) Prevalence of Age-Related Hearing Loss in Older Adults: Blue Mountains Study. Archives of Internal Medicine, 169, 415-416. 
https://doi.org/10.1001/archinternmed.2008.597

[22] Lasisi, A.O., Abiona, T. and Gureje, O. (2010) The Prevalence and Correlates of Self-Reported Hearing Impairment in the Ibadan Study of Aging. Transactions of The Royal Society of Tropical Medicine and Hygiene, 104, 518-523.

https://doi.org/10.1016/j.trstmh.2010.03.009

[23] Sogebi, O.A. (2013) Assessment of the Risk Factors for Hearing Loss in Adult Nigerian Population. Nigerian Medical Journal, 54, 244-249. https://doi.org/10.4103/0300-1652.119648

[24] Ilesh, P. and Sheila, K.W. (2007) Presbyopia: Prevalence, Impact, and Interventions. Community Eye Health Journal, 20, 40-41. 


\section{Appendix I}

Questionnaire for Early on Set Age Related Hearing Loss Survey

Personal Data

Date: ID Number:

Age: Sex: state of origin

Ethnicity:

Address:

Mobile phone:

Occupation:

Hearing Related Past Medical History

Do you or ever had:

A discharging ear

Ear surgery

Noise in the ear

Measles

Mumps

Ear problem after medication

Hearing loss in the family

yes

yes

yes

yes

yes

yes

yes Marital Status

Others:

Syphilis, TB, etc.

Repeated exposure to:

Loud noise

no yes if yes Specify

Motorcycles

$$
\text { yes }
$$
no

Others

\section{Medical History}

Have you a medical history of any of these

1) Previous stroke

2) Neck/head injury

3) Diabetes

4) Hypertension

5) Smoking

Examination Findings

(RIGHT)

(LEFT)

EAC

TM

RINNE

WEBER

ASSESSMENT

QUALIFY

AUDIOMETRY

TYMPANOMETRY 


\section{DIAGNOSIS}

Thank you for participating

\section{Dr. Folorunso David Femi}

Designed by myself and the co-authors. The validity and reliability was tested before the beginning of the study. 